\title{
NEW PLACE DESIGNS WITH EMERGING TECHNOLOGIES
}

\author{
NING GU \\ School of Architecture and Built Environment \\ University of Newcastle \\ University Drive, Callaghan, NSW 2308, Australia \\ ning.gu@newcastle.edu.au
}

\author{
MARY LOU MAHER \\ Key Centre of Design Computing and Cognition \\ Faculty of Architecture, Design and Planning \\ University of Sydney \\ NSW 2006, Australia \\ mary@arch.usyd.edu.au
}

\begin{abstract}
The emergence of digital and computing technologies is arguably the force of the century for innovation in all domains. In design, researchers and practitioners have shown an increasing interest in predicting and examining the effect of these technologies in transforming our everyday life and surroundings. Built environments as an essential part of our holistic living environment have played an important role in this revolutionary process. While many have laid out the vision, we are now looking for the integration and extension of this vision with respect to our traditional notions of place. Rather than seeing the future of built environments as a more confusing array of computers and cables, this paper presents three different types of digital and computing technologies and discusses their applications in defining new place designs where the digital and computing technologies become design elements suggesting exciting new resources and languages for exploring built environment designs. For design education, the further understanding and application of these new technologies in design will provide opportunities as well as challenges for future teaching curriculum. The integration of teaching these technologies as new subject areas will prepare the future generations of designers to develop the understanding and skills of designing with and for the new technologies.
\end{abstract}

Keywords: Built environment design; digital media; cyberspace; responsive environments.

\section{Introduction}

In the $21^{\text {st }}$ century, our living is inseparable from digital and computing technologies. In design, researchers and practitioners have shown an increasing interest in predicting and examining the effect of these technologies in transforming our everyday life and surroundings, notably in William J. Mitchell's epic trilogy: City of Bits (1995), e-topia (1999) and Me++ (2003). Built environments as an essential part of our holistic living environment has played an important role in this revolutionary process. While many have laid out the vision, we are now looking for the 
integration and extension of this vision with respect to our traditional notions of place. Rather than seeing the future of built environments as a more confusing array of computers and cables, this paper presents three different types of digital and computing technologies and discusses their applications in defining new place designs where the digital and computing technologies become design elements suggesting exciting new resources and languages for exploring built environment designs. We perceive built environments as a new kind of (1) media place; (2) augmented reality place; and (3) curious responsive place.

For design education, as the digital and computing technologies are gradually redefining and reshaping the environments we inhabit, the further understanding and application of these new technologies in design will provide opportunities as well as challenges for future teaching curriculum. The integration of these technologies as new subject areas will prepare the future generations of designers to develop the understanding and skills of designing with and for the new technologies.

\section{Built Environments as a New Kind of Media Place}

Media, and now digital media are traditionally understood as information about some aspect of the world or about the procedures involved within a specific organization. The key concept of this traditional understanding is that media is about something else and separate from the thing it describes. Digital media being "digital" is often understood as being opposed to something that is "physical". We challenge this idea with a concept of place in which the "digital" is merged with the "physical": digital media play a role in defining the space in which we inhabit by integrating physical objects and place making elements such as walls and doors with digital information visualization and sonification.

\section{1 "Stepping out" of Computer Workstations}

Imagine the built environments become the interface to communicating remotely with friends, accessing information, executing computer programs, and collaborating on projects, without long hours of sitting and staring in front of computer screens. With the advancement of mobile, ubiquitous and tangible computing, digital information is able to "step out" of the traditional workstations and even to be scattered around us.

New information visualization techniques have enabled time-varying commercial datasets to be visualized and analyzed as spatial elements rather than conventional bars and charts. A person can become fully immersed in the dataset by wearing a head-mounted display device and, as such, the process of data analysis becomes the experience of space exploration. Such a visualization system has been applied to stock market quote price datasets (Vande Moere, 2004) and specific knowledge management datasets within a global engineering consultancy firm (Vande Moere et al, 2004).

Smart objects like Ambient Orb ${ }^{1}$ and Nabaztag Smart Rabbit ${ }^{2}$ can bring so-called "ambient information" into built environments. The Ambient Orb, for example, glows in different colors to notify you about the health of your stock portfolio, the changes of weather or the presence of your online contacts. Nabaztag Smart Rabbits will not only glow with different color patterns, but "talk", "sing" and even "wiggle ears" to keep you apprised about different information.

To take this smart object idea further, researchers at the MIT Media Lab developed a device that can turn a physical object into an interface to digital information (Carvey et al, 2006). The traditional portals to digital information have been fixed on computer workstations. As a result, our interactions with digital information have been reduced down to certain direct operations on these workstations regardless the meaning and context of the information. The key idea of this research is to break free the limitations imposed by the workstation concept and to propose new ways of interacting with digital information. For example, as demonstrated in this project, any object in a physical environment can become the interface to open a specific computer file, to modify a digital document, to send an email, or to execute a computer application. This flexible association of digital information and everyday physical objects further blurs the boundary between the physical world and the digital world.

As contemporary living demands increasing levels of computer skills from people, there are general concerns regarding the effort and sometimes even stress on the general public in order to cope with the rapid development of digital and computing technologies. To address these concerns, researchers are developing multi-modal interfaces aiming to provide computing technologies that are more intuitive and user-friendly. These interfaces allow people to interact with digital information through means that we have well mastered, for example, gestures, 
speech, and the manipulation of tangible objects in place of the current interactions through mouse and keyboard. Developing tangible user interfaces - physically touching, grasping, pointing and dragging physical objects on a digital workbench - is one possible way forward. Figure 1 shows a digital workbench integrated with table-size touch screen and augmented reality technologies, for design and collaboration with digital models (Dong et al, 2006; Maher and Kim, 2006).
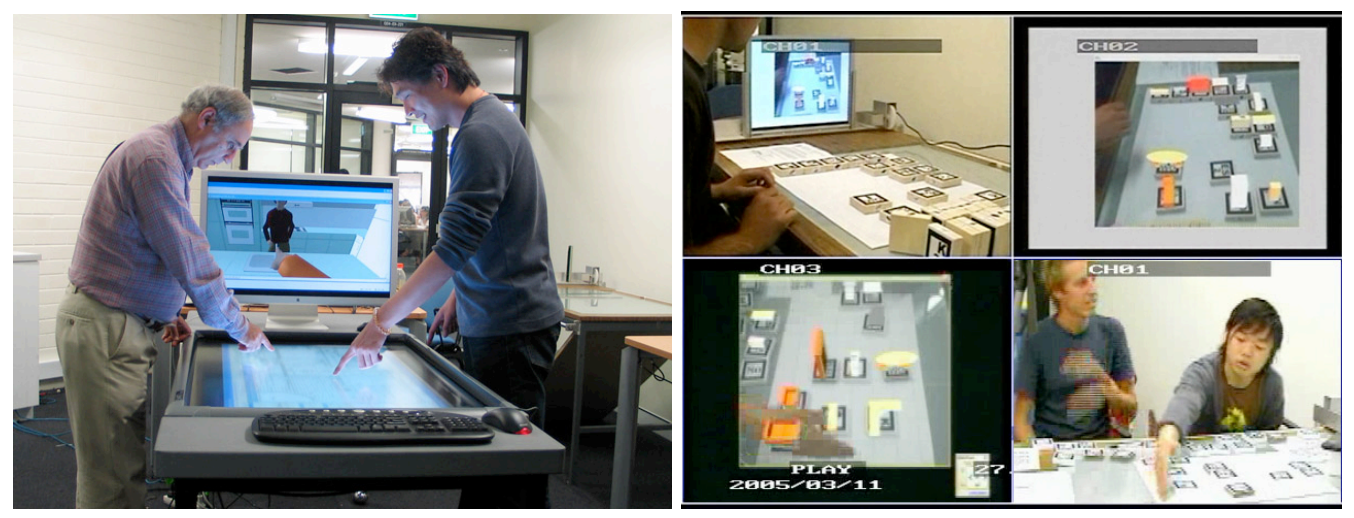

Figure 1: A digital workbench for design and collaboration

\subsection{Digital Media as New Design Elements for Built Environments}

With digital media being able to "step out" of computer workstations, the traditional separation of the objects that display digital information and the elements that make up the design of built environments will be eliminated. In the future, these two will be seamlessly merged.

One of the early attempts to bind digital media with design elements was media façade; a technique that has been widely embraced by contemporary architects and artists. Media façades used in architecture and art installations can be seen in the Kunsthaus $\mathrm{Graz}^{3}$, the Blinkenlights project for Haus des Lehrers office building at Berlin Alexanderplatz ${ }^{4}$, and Monuments of Switzerland art installation on giant cooling towers.

Similar concepts have been developed for interior design elements. Activity Wallpaper ${ }^{5}$, for example, provides an ambient display, which can visualize and respond to indoor activities such as the changes of crowds and noise levels. Not So White Walls ${ }^{6}$ can display a person's email, SMS and webcam images. In Weather Patterns ${ }^{7}$ (Figure 8), a permanent installation at the York Art Gallery, UK, the windows become the devices for visualizing the changing weather patterns.

Technologies enabling these new design elements to be interactive have further enhanced the experiences from media place. For example, the SmartSlab ${ }^{8}$ and Lightspace ${ }^{9}$ technologies $^{-}$ provide interactive display technology within a vertical or horizontal solid structure that can be used as walls or floors that respond to the presence and movement of the inhabitants. Different design elements of built environments now can also have Radio Frequency Identification (RFID) tags for automatic location and cataloguing of information about the place. The Media House Project (Guallart, 2004) pushes the media place concept to the extreme by literally constructing a "computer" using building elements. The project implemented a prototype of a media place filled with digital information where "house is the computer and its structure".

\section{Built Environment as a New Kind of Augmented Reality Place}

Cyberspace, as first introduced in the science fiction novel Neuromancer (Gibson, 1984), has become accessible in the past two decades through the world wide web. It has gradually become an important part of the holistic living environments we inhabit supporting everyday economic, cultural, educational and other human activities. Cyberspace distinguishes itself from other networked technologies by having place characteristics. It is not just another communication tool but the "ultimate destination" where we shop, are entertained and get educated (Kalay and Marx, 2001). 


\subsection{Cyberspace}

The development of built environments used to mean its physical expansion - larger space and added extension. With the evolution of cyberspace technologies as well as the booming of online community and activities: e-business, e-learning and e-entertainment, the future will see an increasing use of cyberspace as an important extension of our physical world. We will be spending increasing amount of time in cyberspace. Therefore, designing cyberspace will potentially become an important design topic, which deserves better understanding and indepth exploration.

Asymptote principle architect Hani Rashid ${ }^{10}$ designed the virtual trading floor for the New York Stock Exchange (NYSE). The design incorporates and visualizes the virtual booths as well as interactive graphs within the virtual place, which simulates but, more importantly, extends, the physical trading floor.

One important characteristic of the contemporary world is the ability to be distributed. Societies, corporations and individuals are remotely linked together with the support of telecommunications. While the use of teleconferencing and videoconferencing facilities allow you to reach for collaborators in different geographical locations, Cyberspace extends our built environments into the virtual realm with augmented place and augmented presence.

In a series of joint studies, researchers at the University of Sydney and architects at Woods Bagot, have looked at the prospects of using cyberspace to augment architectural design offices for remote team collaboration (Rosenman et al, 2005). Figure 2 shows architects working together in a range of remote collaborative situations in a 3D virtual world.

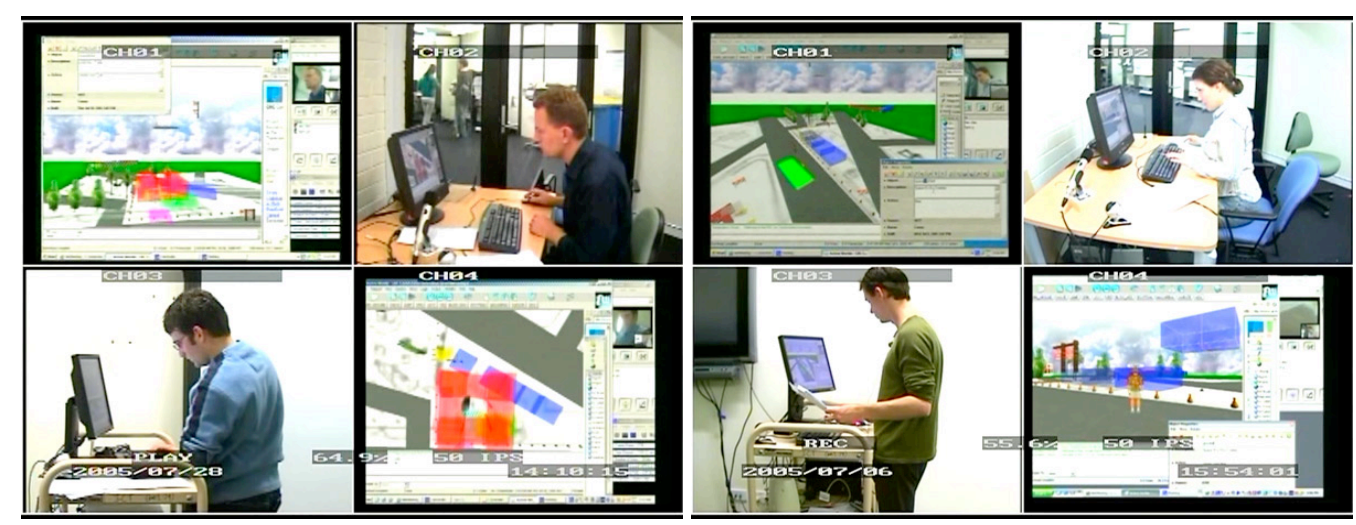

Figure 2: Remote team collaboration using cyberspace

\subsection{D Electronic Institutions}

After the fear engendered by the September 11 attacks and the questions surrounding the value of centralized business districts (such as downtown Manhattan ${ }^{11}$ ), experts from the domains of sociology, business and design have been seeking alternatives to such central business districts and considering the question: Will virtual organizations be "the next big thing"?

The places in cyberspace may be virtual, but the community and the economy in cyberspace are real and are growing rapidly. For example, virtual worlds like Second Life ${ }^{12}$ (Figures 3 ) have attracted millions of members. The virtual organizations range from property investment, travel agencies, entertainment industries to academic and research institutes. Communities in Second Life even use their own currency, which is exchangeable with US dollars, and maintains their own stock market. 

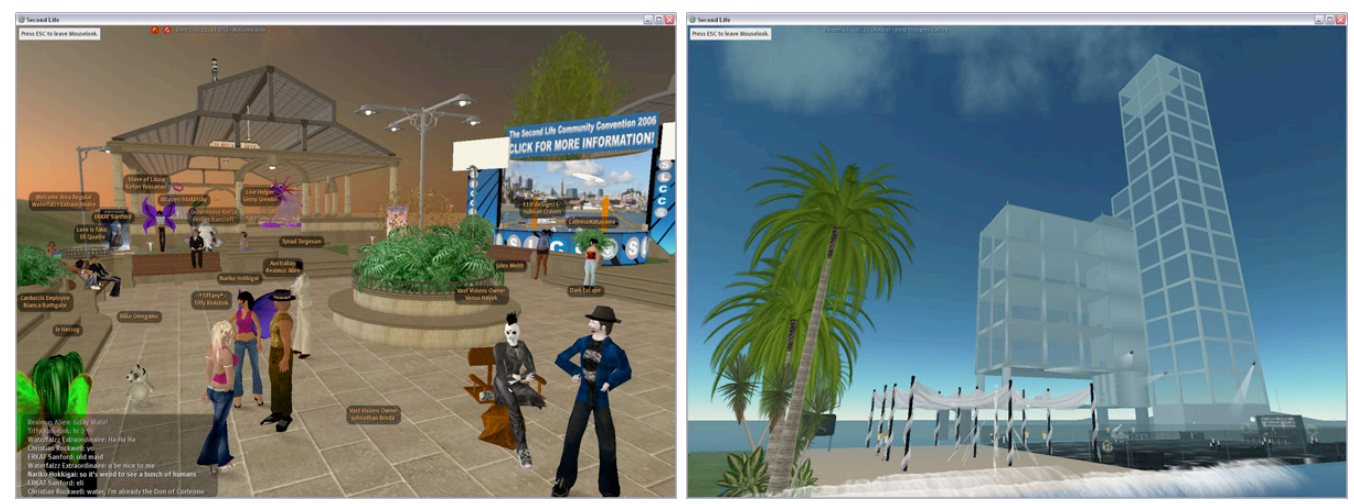

Figure 3: Community members gather for a Second Life convention (L), A newly built virtual office building for rent $(R)^{13}$

To better support virtual organizations in cyberspace and, working together with computer scientists from the University of Technology, Sydney (UTS), we have developed the concept of 3D electronic institutions (Bogdanovych et al, 2007). The key advantage of 3D electronic institutions is the existence of a $3 \mathrm{D}$ virtual world with an underlying computer agent framework that ensures secure online activities and reinforces organizational structures. The 3D virtual world is automatically designed and redesigned, as needed, using a design grammar ( $\mathrm{Gu}$ and Maher, 2005), providing an adaptable virtual world for the electronic institutions.

\section{Built Environments as a New Kind of Curious Responsive Place}

Built environments are traditionally perceived as a passive environment that requires direct modification in order to respond to changes or user needs. However, with sensor and effector technologies, and the development in artificial intelligence, it is possible to create environments that can respond to changes and user needs without direct modification. This section presents these ideas in two phases: "responsive environments" that have a fixed response to their inhabitants, and "curious places" that are interested in reasoning about changes in the use of the places.

\subsection{Responsive Environments}

Imagine that the lighting, temperature and the layout of the environments you inhabit automatically adjust according to your presence; the relevant resources and applications selectively cluster and present themselves according to your living/working mode; your personal environment emits ambient information for your interest. Phenomena like these will significantly affect the way we perceive, design and inhabit built environments.

Built environments are generally passive. But, when integrated with new technologies like (1) sensory devices that can be spatially and socially triggered; (2) video tracking and data capture devices; (3) pervasive mobile computing devices; as well as (4) ambient visual and auditory displays, built environments will be able to actively interact with their inhabitants. Those new objects and design elements introduced in section 2 are in fact example applications of such technologies, and will contribute to the making of responsive environments. With the further development of responsive place making, it is possible to upgrade buildings like Jean Nouvel's ${ }^{14}$ L'Institut du Monde Arabe to enable auto-adjustments of the diaphragms on its façade to allow dynamic control of the sunlight penetration into the interior, without specific manual operations.

\subsection{Curious Places}

Responsive environments are indeed intelligent environments. However, some researchers are interested in pushing the level of intelligence further. With the integration of intelligent agent technologies and learning algorithms, built environments can become curious by taking an interest in the inhabitants, learning about their behavioural patterns and trying to provide better services.

In the context of computing, agents are intentional systems that operate independently and rationally, seeking to achieve goals by interacting with their environments (Wooldridge and Jennings, 1995). While agent-based computing started in the 1970s, recently the concept of 
agents has become important for computing applications, drawing on ideas from artificial intelligence and artificial life.

A possible application of curious places is the development of built environments as intelligent assistants. For example, in an office environment, the environment is able to learn about the behavioural patterns of employees and their project work flows; then (on a grander scale) dynamically coordinate public and shared spaces for communal uses; or (on a more intimate scale) personalize individual work environments, customise working platforms and datasets, or even simulate and automate selected work tasks.

In the Key Centre of Design Computing and Cognition, a long-term research project titled "Curious Room" develops a motivated learning agent, which learns actively from its environments through intrinsic rewards (Saunders et al, 2007). The agent is capable of operating in "the Sentient", a sensate room incorporated with pressure-sensitive pads for tracking the presence and locations of people in the room (Figure 4). Our current case study shows that the agent is able to learn about the moving patterns of people in the room and actively composes and shows visual displays according to its learning outcomes.
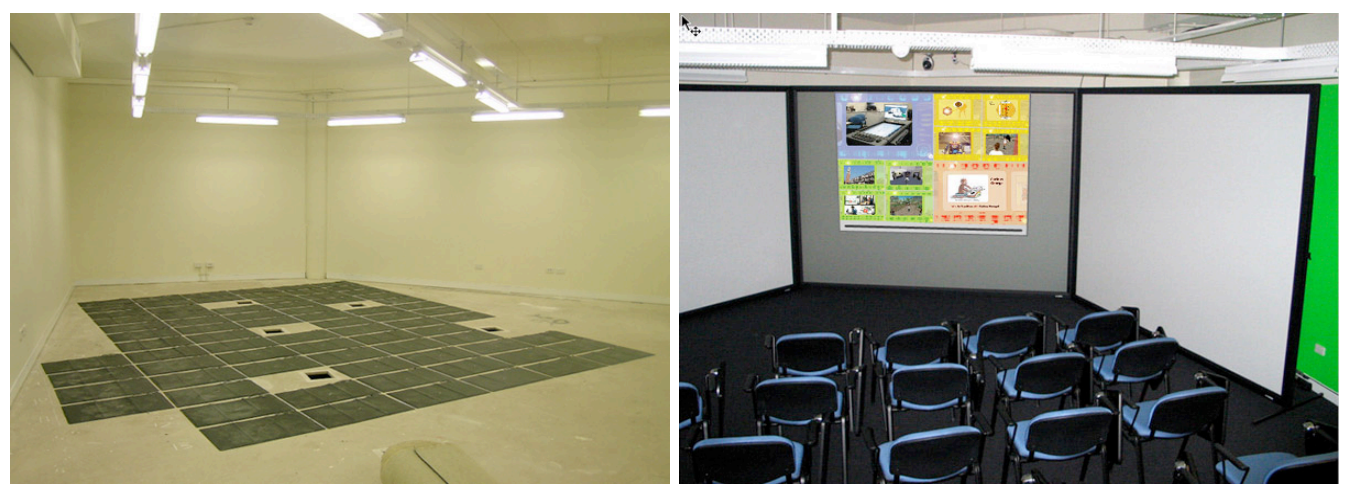

Figure 4: The pressure sensitive pads placed underneath the carpet (L), "The Sentient" with completed flooring (R)

The further development of this research will see the motivated learning agent taking more proactive actions in adjusting the environmental conditions of the room and assisting meeting/seminar setups and configurations.

\section{Conclusion}

As presented in this paper, the emerging digital and computing technologies as new design elements for making media places, augmented reality places and curious responsive places have illuminated interesting ideas and potentials for built environment designs. They suggest exciting new design resources and languages for exploring future alternatives. These three kinds of new places and the emerging technologies applied for designing them can serve as a starting point for further research, practice and validation of using digital and computing technologies in built environment designs.

For design education, as new digital and computing technologies emerge, the further understanding and application of these technologies in built environment designs will enrich and innovate the current teaching curriculum. One important step to such pedagogical innovation is to develop the conceptual shift regarding the roles of digital and computing technologies in design. Within many architecture and design schools, digital and computing technologies are traditionally perceived and mainly used as CAD tools for design presentations and documentations. The teaching of these technologies often separates from the teaching of design. It is important to recognise and understand the roles of digital and computing technologies in design as well as to foresee their full potentials beyond design presentations and documentations. As shown in this paper, the contemporary and future built environment designs are closely connected with and may even be driven by these new technologies. They can have significant impacts redefining and reshaping built environment designs. We are currently experimenting on the teaching of these new technologies as design subjects and planing on their integrations into the current architecture and design teaching curriculum. For example, unlike many other architecture and design schools where cyberspace technologies 
such as 3D virtual worlds are perceived and taught as a CAD tool for modelling and collaboration, we build on the understanding of $3 D$ virtual worlds as the extension of our physical environments where people can inhabit and participate in a wide variety of activities, and teach designing 3D virtual worlds as a design subject that considers 3D virtual worlds as a different kind of environment design other than a technical tool for supporting design simulation and collaboration ( $\mathrm{Gu}$ et al, 2007). Our approach that regards 3D virtual worlds as a design discipline adds new dimensions to the development of cyberspace for built environment designs. The teaching of digital and computing technologies as design subjects will prepare future generations of designers to develop the understanding and skills of designing with and for the new technologies. The emergence and further integration of these subjects with the current teaching curriculum will suggest new opportunities and challenges for architecture and design education.

\section{Acknowledgements}

The authors would like to thank Dr. Andrew Vande Moere for his lectures on information visualization research and technologies and specifically his introduction to the following information visualization projects: Monuments of Switzerland; Activity Wallpaper; Not So White Walls; and Weather Patterns.

\section{Notes}

1 http://www.ambientdevices.com

2 http://www.nabaztag.com

${ }^{3}$ http://www.bix.at

${ }^{4}$ http://www.blinkenlights.de

${ }^{5}$ http://www.viktoria.se/fal/projects/infoart

${ }^{6}$ http://people.interaction-ivrea.it/d.buzzini

${ }^{7}$ http://loop.ph/twiki/bin/view/Loop/WeatherPatterns

${ }^{8}$ http://www.smartslab.co.uk

${ }^{9}$ http://www.lightspacecorp.com

${ }^{10} \mathrm{http}: / / \mathrm{www}$.asymptote.net

${ }^{11} \mathrm{http}: / /$ www.evolvenewyork.org

12 http://www.secondlife.com

${ }^{13}$ Places in Second Life by its virtual community designers, powered by Linden Research, Inc.

${ }^{14}$ http://www.jeannouvel.com

\section{References}

Bogdanovych, A, Esteva, M, Gu, N, Simoff, S, Maher, ML and Smith, G. "The Role of Online Travel Agents in the Experience Economy." Proceedings of the 14th International Conference on Information Technology and Travel \& Tourism (ENTER 2007). UK: Axon Imprint, 2007, pp. 81-91.

Carvey, A, Gouldstone, J, Vedurumudi, P, Whiton, A and Ishii, $H$. "Rubber Shark as User Interface." Extended Abstracts of Conference on Human Factors in Computing Systems (CHI '06). Montréal, 2006.

Dong, A, Maher, ML and Daruwala, Y. "Construction Defect Reporting Using Mobile and Digital Workbench Technologies." Proceedings of Joint International Conference on Computing and Decision Making in Civil and Building Engineering. Montréal, 2006, pp. 3597-3606.

Gibson, W. Neuromancer. New York: Ace Books, 1984.

Gu, N, Gul, LF and Maher, ML. "Designing and Learning Within the Design: a Case Study of Principles for Designing and Teaching 3D Virtual Worlds." Proceedings of Computer Aided Architectural Design Research in Asia Conference (CAADRIA 2007). Nanjing, 2007. 
Gu, N and Maher ML. "Dynamic Designs of 3D Virtual Worlds Using Generative Design Agents." Proceedings of Computer Aided Architectural Design Futures Conference (CAADFutures 2005). Dordrecht: Springer, 2005, pp. 239-248.

Guallart, V, ed. Media House Project. Barcelona: Actar, 2004.

Kalay, YE and Marx, J. "Architecture and the Internet: Designing Places in Cyberspace." Proceedings of Association for Computer Aided Design in Architecture Conference (ACADIA 2001). Buffalo, 2001, pp. 230-240.

Maher, ML and Kim, MJ. "Studying Designers Using a Tabletop System For 3D Design With a Focus on the Impact On Spatial Cognition." Proceedings of IEEE International Workshop on Horizontal Interactive Human-Computer Systems (Tabletop 2006). IEEE, Adelaide, Australia, 2006, pp. 105-112.

Mitchell, WS. Me++. Cambridge: The MIT Press, 2003.

Mitchell, WS. e-topia. Cambridge: The MIT Press, 1999.

Mitchell, WS. City of Bits, Cambridge: The MIT Press, 1995.

Rosenman MA, Smith G, Ding L, Marchant D and Maher ML. "Multidisciplinary Design in Virtual Worlds." Proceedings of Computer Aided Architectural Design Futures Conference (CAADFutures 2005). Dordrecht: Springer, 2005, pp. 433-442.

Saunders, R, Merrick, K, and Maher, ML. "Curious Places: Curious, Proactive, Adaptive Built Environments." Proceedings of the Symposium on Agent Societies for Ambient Intelligence (AISB'07). Newcastle, 2007.

Vande Moere, A. "Time-Varying Data Visualization using Information Flocking Boids." Proceedings of IEEE Symposium on Information Visualization (INFOVIS'04). Austin, 2004, pp. 97-104.

Vande Moere, A, Mieusset, KH, Gross, M. "Visualizing Abstract Information using Motion Properties of Data-Driven Infoticles." Proceedings of Conference on Visualization and Data Analysis 2004 - IS\&T/SPIE Symposium on Electronic Imaging. San Jose, 2004, pp. 33-44.

Wooldridge, $\mathrm{M}$ and Jennings, NR. "Intelligent Agents: Theory and Practice." Knowledge Engineering Review . 10(2) (1995): 115-152. 